\title{
Are lycopene metabolites metabolically active?*
}

\author{
Nikki A. Ford ${ }^{1}$ and John W. Erdman, Jr. ${ }^{2,3 凶}$ \\ 1Department of Nutritional Sciences, University of Texas, Austin, TX USA; ${ }^{2}$ Division of Nutritional Sciences, University of IIlinois, Urbana, IL USA; \\ 3Department of Food Science and Human Nutrition, University of Illinois, Urbana, IL USA
}

\begin{abstract}
Lycopene is the most abundant carotenoid found in tomatoes and thus has been touted as the bioactive component for the reduced risk of chronic diseases such as prostate cancer. We and others hypothesize that lycopene metabolites are responsible for positively modulating biomarkers and risk factors for the prevention of chronic diseases. Lycopene metabolites circulate in serum and accumulate in tissues at concentrations equivalent to bioactive retinoids. Recent studies report that lycopene metabolites reduce the proliferation of cancer cells, induce apoptosis, enhance gap junction communication between cells, alter normal cell cycle progression, and modulate androgen signaling pathways. Here we review recent literature and provide new evidence to suggest that lycopene metabolites may be bioactive at physiological concentrations.
\end{abstract}

Key words: lycopene, carotene-monooxygenase, lycopenoids, testosterone

Received: 13 October, 2011; accepted: 01 March, 2012; available on-line: 17 March, 2012

\section{INTRODUCTION}

Epidemiological evidence suggests that consumption of lycopene, the red pigment of tomato products and a major carotenoid in human plasma and tissues, is inversely associated with the risk for a number of pathologies including most notably prostate cancer (Giovannucci et al., 1995; Canene-Adams et al., 2005). Based upon recent advances in understanding carotenoid metabolism, we hypothesize that lycopene metabolites may be responsible, at least in part, for this association.

In this review, we will show that lycopene metabolites circulate in serum and accumulate in tissues at physiologically-relevant concentrations in comparison to retinoids, establish that lycopene metabolites are biologically active, and introduce new findings that suggest these metabolites alter serum testosterone levels which are an important risk factor for prostate cancer.

\section{LYCOPENE METABOLITES}

Lycopene metabolites, also termed lycopenoids, are poly-isoprenoid compounds of less than 40 carbons in length derived from the parent compound, lycopene (Lindshield et al., 2007). Previous studies identified and characterized lycopenoids and oxidation products generated in vivo; some of these metabolites demonstrate anticancer activity by inhibiting proliferation, inducing apoptosis, or enhancing cell to cell communication (King et al., 1997; Zhang et al., 2003; Ford et al., 2011a).
A series of apo-lycopenals and short-chain carbonyl compounds were produced by in vitro autoxidation of lycopene including apo-14'-lycopenal, apo-12'-lycopenal, apo-10'-lycopenal and apo-6'-lycopenal (Kim et al., 2001). Additional studies have identified other apo-lycopenals in vitro (Khachik et al., 1998a; Khachik et al., 1998b; CarisVeyrat et al., 2003). Although there are problems associated with the use of in vitro models for this type of work, the chemicals formed in vitro may be important representatives of carotenoid cleavage in the lungs of smokers, tumors in cancer patients, or other oxidatively stressed conditions (Ford et al., 2011a).

Metabolites of lycopene have also been identified in vivo and interestingly, concentrations of lycopenoids are of comparable biological concentrations to retinoids produced from $\beta$-carotene (Table 1). Since all trans retinoic and 9 -cis retinoic acids are important ligands for a variety of nuclear receptors, it is certainly plausible that some lycopenoids that have similar structure, polarity and molecular weights may be antagonists or agonists to some receptors.

\section{LYCOPENE METABOLISM}

Chain-shortened lycopene products may be produced by free radical oxidation, lipoxygenase activity, phase II detoxification enzymes, or carotenoid cleavage enzymes (see Mein et al., 2008 for review). Enzymatic carotenoid metabolism is primarily catalyzed by two carotenoid monooxygenase enzymes, carotene-15,15'-monooxygenase (CMO-I) and carotene- 9 ' $10^{\prime}$-monooxygenase (CMO-II). CMO-I centrally cleaves carotenoids, such as $\beta$-carotene (Hessel et al., 2007) whereas CMO-II primarily eccentrically metabolizes non-provitamin A carotenoids like lycopene (Hu et al., 2006; Ford et al., 2010). The expression of these carotenoid cleavage enzymes is differentially expressed in tissues (Table 2). The products of CMOII are short chain aldehydes termed apo-lycopenals. As previously noted, apo-lycopenals have been identified in vivo at physiologically relevant concentrations (Table 1).

Recent studies from our lab and others have demonstrated that dietary lycopene alters the mRNA expression of CMO-II in animal models. We measured the relative mRNA expression of CMO-II by qRT-PCR in healthy prostate tissue and prostatic tumor from male Copenha-

\footnotetext{
e-mail: jwerdman@illinois.edu
}

*Presented at the 16th International Symposium on Carotenoids, 17-22 July, 2011, Kraków, Poland

Abbreviations: AIN-93G, American Institute for Nutrition 1993 growth formula; CMO-I, carotene-15,15'-monooxygenase; CMOII, carotene-9',10'-monooxygenase; DHT, dihydrotestosterone; KO, knock-out; Nrf2, nuclear factor E2-related factor 2; qRT-PCR, quantitative real time polymerase chain reaction. 
Table 1. Tissue and serum concentrations of lycopene and $\beta$-carotene metabolites.

\begin{tabular}{llll}
\hline Metabolite & Animal & Tissue & Concentration \\
\hline Apo-6'-lycopenal & Humans & Plasma & $0.076 \mathrm{ng} / \mathrm{ml}$ \\
Apo-8'-lycopenal & Rats & Liver & $250 \mathrm{ng} / \mathrm{g}$ \\
Apo-8'-lycopenal & Humans & Plasma & $0.142 \mathrm{ng} / \mathrm{ml}$ \\
Apo-10'-lycopenal & Humans & Plasma & $0.076 \mathrm{ng} / \mathrm{ml}$ \\
Apo-12'-lycopenal & Rats & Liver & $\geq 250 \mathrm{ng} / \mathrm{g}$ \\
Apo-12'-lycopenal & Humans & Plasma & $0.137 \mathrm{ng} / \mathrm{ml}$ \\
Apo-10'-lycopenol & Ferrets & Lung & $2-4 \mathrm{ng} / \mathrm{g}$ \\
Retinal & Rats & Intestine & $8 \mu \mathrm{gg} / \mathrm{g}$ \\
All-trans-Retinoic Acid & Humans & Plasma & $3.5 \mathrm{ng} / \mathrm{ml}$ \\
All-trans-Retinoic Acid & Rats & Plasma & $1.2 \mathrm{ng} / \mathrm{ml}$ \\
$\beta$-apo-8'-carotenal & Humans & Plasma & $245 \mathrm{ng} / \mathrm{ml}$ \\
\hline
\end{tabular}

(De Leenheer et al., 1982; Gajic et al., 2006; Hu et al., 2006; Kopec et al., 2010)

gen rats in response to a $10 \%$ tomato powder diet or a control AIN-93G diet (Fig. 1). Quantification of CMOII mRNA expression was described previously (Ford et al., 2011b), the data was analyzed by student's $t$-test, and $p<0.05$ was considered statistically significant. The tomato powder diet significantly reduced the expression of CMO-II in healthy prostate tissue. However, in prostatic tumor tissue, the tomato powder diet induced mRNA expression of CMO-II relative to tissues of rats that were fed the control diet. In addition, we demonstrated that a lycopene-enriched diet significantly reduced the expression of CMO-II in renal tissue of F344 rats which we hypothesize was the result of feedback inhibition by lycopene or its metabolites (Zaripheh et al., 2006). In a study from another laboratory, dietary lycopene increased the expression of CMO-II mRNA by 4-fold in the lungs of ferrets (Hu et al., 2006). The apparent contradictions in these data sets suggest to us that these are tissue specific metabolic and/or oxidative environments that affect lycopene catabolism and/or the possible differential need for lycopene metabolites by specific tissues. We hypothesize that highly oxidative conditions such as lung and tumor tissue may produce or require greater concentrations of lycopene metabolites and therefore inducing CMO-II expression in these tissues. Overall, the effect of carotenoid consumption on the expression of carotenoid cleavage enzymes warrants further investigation.

Table 2. Relative tissue mRNA expression of CMO-II in mouse and human tissues.

CMO-II expression was analyzed by qRT-PCR using SYBR green fluorescence as described previously (Ford et al., 2011b) and compared to published literature (Wyss 2004; Lindqvist et al., 2005).

\begin{tabular}{llll}
\hline Tissue & $\begin{array}{l}\text { Mouse } \\
\text { (new data) }\end{array}$ & $\begin{array}{l}\text { Mouse } \\
\text { (literature) }\end{array}$ & $\begin{array}{l}\text { Human } \\
\text { (literature) }\end{array}$ \\
\hline Liver & ++ & +++ & +++ \\
Duodenum & +++ & +++ & +++ \\
Prostate & ++ & $\mathrm{N} / \mathrm{A}$ & ++ \\
Testes & $+^{*}$ & ++ & ++ \\
Adrenals & N/A & ++ & N/A \\
\hline
\end{tabular}

$(\mathrm{N} / \mathrm{A})$ not available, $(+)$ low, $(++)$ moderate, $(+++)$ high expression levels. ${ }^{*}$ ) Published previously (Ford et al., 2011b).

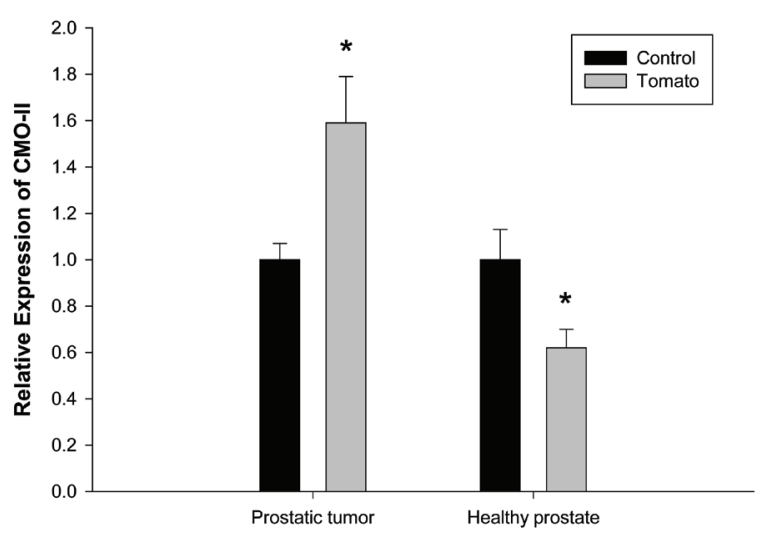

Figure 1. Relative CMO-II mRNA expression.

Prostate and prostatic tumor tissue express CMO-II but expression is differentially affected by consumption of a $10 \%$ tomato powder diet containing approximately $13 \mathrm{nmol}$ lycopene per gram of diet. Quantitative RT-PCR analysis of the carotenoid monooxygenase II (CMO-II) was carried out in healthy rat prostatic tissue and prostatic tumor tissue from Dunning R3327-H prostate adenocarcinoma orthotopic transplant in male Copenhagen rats. mRNA expression is expressed relative to the ribosomal gene, 18S. Expression of CMO-II in each tissue was analyzed by student's $t$-test; $\left(^{*}\right)$ $p<0.05$ considered statistically significant.

\section{BIOLOGICAL ACTIVITY OF APO-LYCOPENALS AND APO-LYCOPENOIC ACIDS}

Recent strong scientific interest in lycopene metabolism has produced some early evidence to suggest that lycopenoids are biologically active. We recently reported that apo- $10^{\prime}$-lycopenal and apo- $12^{\prime}$-lycopenal treatment reduced DU145 prostate cancer cell proliferation in a dose-dependent manner in part through regulation of the normal cell cycle (Ford et al., 2011a). A separate group demonstrated that apo-10'-lycopenoic acid reduced proliferation of lung cancer cells and tumorigenesis of an in vivo lung tumor mouse model through Nrf2-mediated induction of phase II detoxifying/antioxidant enzymes (Lian et al., 2007). Future studies will further define the biological benefits of lycopenoids.

\section{BIOLOGICAL ACTIVITY OF LYCOPENE OXIDATION PRODUCTS}

Products produced from lycopene through a variety of oxidative procedures have been reported to modulate biological activity. It has been demonstrated that oxidation products of lycopene inhibit the growth of human leukemia cells in vitro (Nara et al., 2001). Specifically, $6 \mu \mathrm{M}$ of lycopene failed to alter leukemia cell proliferation while $6 \mu \mathrm{M}$ of oxidative lycopene products (produced from incubation with toluene for 24 hours) dramatically inhibited cell growth by $97 \%$ relative to control after 120 hours in culture. In human promyelocytic leukemia cells, a different oxidative product, (E,E,E)-4-methyl-8-oxo-2,46-nonatrienal $(5-15 \mu \mathrm{M})$, also reduced proliferation and induced the essential physiological mechanism to remove damaged DNA by apoptosis (Zhang et al., 2003). In contrast, lycopene treatment alone did not affect apoptosis and had little effect on proliferation rates. Other oxidative products of lycopene have also been shown to inhibit prostate cancer cell growth through induction of apoptosis (Kotake-Nara et al., 2002). In another study, a solution of undefined lycopene oxidative products stimu- 
lated gap junction communication which is essential to reduce overgrowth of cells as typically found in cancerous tissues (Aust et al., 2003). Another lab demonstrated that an ethanol extract of oxidized lycopene activated the electrophile/antioxidant response element which is known to induce phase II detoxification enzymes in human mammary cancer cells (Linnewiel et al., 2009).

Early studies are starting to suggest that lycopene metabolites play a role in preventing or moderating certain cancer types. Therefore, identification of bioactive lycopene metabolites and further characterization of their in vivo function(s) is critical for cancer research.

\section{PROSTATE CANCER, TESTOSTERONE AND LYCOPENE METABOLITES}

Prostate cancer risk is positively associated with induced androgen signaling (Gann et al., 1996; Shaneyfelt et al., 2000). It was first reported in 1941 that the reduction of testosterone levels is a potent therapeutic agent for patients with advanced prostate cancer (Huggins et al., 2002). Moreover, a causal relationship was suggested by a few case reports of prostate cancer patients who previously used androgens as anabolic agents or for medical treatment (Roberts et al., 1986; Ebling et al., 1997).

Recently, we established that testosterone levels in our mouse models are dependent upon an interaction of the expression of carotenoid cleavage enzymes and dietary levels of lycopene. Specifically, we reported that tomato powder or lycopene-containing diets reduced serum and testicular testosterone in CMO-I knock out (CMO-I KO) mice (Ford et al., 2011b). It should be noted that the primary site of whole body testosterone production is from the testis tissue and we demonstrated the testis tissue of CMO-I KO mice have significantly elevated expression of CMO-II. Therefore, it is plausible that CMO-I KO mice have elevated production of lycopene metabolites in testis tissue which effectively reduced serum and testicular testosterone concentrations. Here, we further demonstrate in this mouse model that the expression of key testosterone metabolism genes or receptors is significantly reduced in response to a diet

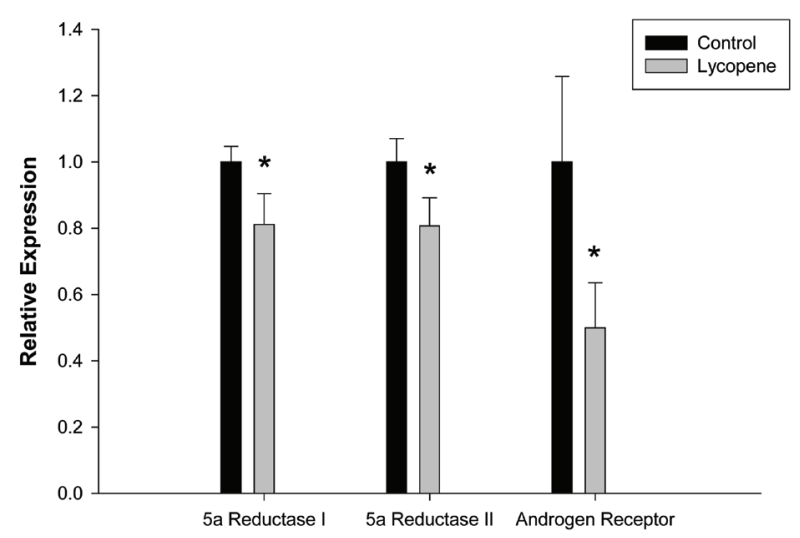

Figure 2. Relative mRNA expression of steroid pathway genes. Testicular 5 alpha reductase I, testicular 5 alpha reductase II, and prostatic androgen receptor are differentially expressed in CMOI knock-out mouse tissues in response to a lycopene-containing diet $(248 \mathrm{nmol} / \mathrm{g}$ diet). CMO-I knock-out mice have significantly elevated expression of testicular CMO-II (Ford et al., 2011b). mRNA expression is expressed relative to the ribosomal gene, 18S. mRNA expression of target genes in each tissue was analyzed by student's t-test; $\left({ }^{*}\right) p<0.05$ considered statistically significant. containing $248 \mathrm{nmol}$ lycopene per gram of diet (Fig. 2). The mRNA expression of testicular 5-alpha reductase I, testicular 5-alpha reductase II, and prostatic androgen receptor was measured by qRT-PCR using the SYBR green dye as previously described (Ford et al., 2010). The conversion of testosterone to its more potent androgen dihydrotestosterone, DHT, is catalyzed by the 5-alpha reductase enzyme. Either testosterone or DHT may bind the androgen receptor thus inducing androgen responsive genes. The significant reduction in the expression of these genes by a lycopene-containing diet suggests a reduction in androgen signaling in the testes and prostate. Therefore, it is conceivable that the enhanced production of lycopenoids in the testis of CMO-I KO mice reduced androgen signaling and therefore may potentially reduce prostate cancer risk.

\section{CONCLUSIONS}

Lycopene metabolites have been identified in vivo in similar concentrations to the biologically active retinoids. Recent reports suggest that lycopenoids reduce proliferation of cancer cells, induce apoptosis, regulate flow through the cell cycle, induce nuclear transcription factors, enhance cell to cell communication, and reduce androgen signaling. The consumption of lycopene containing foods and the tissue specific expression of carotenoid cleavage enzymes determines tissue lycopenoid concentrations. New reports suggest that these lycopenoids are biologically active and may reduce the risk for chronic diseases. We provide data that suggest that lycopeniods influence androgen metabolism in rodent models.

\section{Acknowledgements}

We would like to thank Shih-Hui (Christina) Yang and Dr. Kirstie Canene-Adams for completing the rat feeding study and providing the gene expression data presented in Fig. 1.

Financial Support: NIH grant PHS-1-RO1 CA125384; Dr. Ford was supported by a Blue Cross of Texas Postdoctoral Fellowship.

\section{REFERENCES}

Canene-Adams K, Campbell JK, Zaripheh S, Jeffery EH, Erdman JW Jr (2005) The tomato as a functional food. J Nutr 135: 1226-1230.

Caris-Veyrat C, Schmid A, Carail M, Bohm V (2003) Cleavage products of lycopene produced by in vitro oxidations: Characterization and mechanisms of formation. J Agric Food Chem 51: 7318-7325.

De Leenheer AP, Lambert WE, Claeys I (1982) All-trans-retinoic acid: Measurement of reference values in human serum by high performance liquid chromatography. J Lipid Res 23: 1362-1367.

Ebling DW, Ruffer J, Whittington R, Vanarsdalen K, Broderick GA, Malkowicz SB, Wein AJ (1997) Development of prostate cancer after pituitary dysfunction: A report of 8 patients. Urology 49: 564-568.

Ford NA, Erdman JW Jr (2008) Lycopene metabolites: Apo-lycopenals. Lycopene: Nutr, Med, and Ther Prop 37-63.

Ford NA, Elsen AC, Zuniga K, Lindshield BL, Erdman JW Jr (2011a) Lycopene and apo-12'-lycopenal reduce cell proliferation and alter cell cycle progression in human prostate cancer cells. Nutr Cancer 63: $256-263$.

Ford NA, Moran NE, Smith JW, Clinton SK, Erdman JW Jr (2011b) An interaction between carotene-15,15'-monooxygenase expression and consumption of a tomato or lycopene-containing diet impacts serum and testicular testosterone. Int J Cancer

Ford NA, Clinton SK, von Lintig J, Wyss A, Erdman JW Jr (2010) Loss of carotene-9',10'-monooxygenase expression increases serum and tissue lycopene concentrations in lycopene-fed mice. J Nutr 140: 2134-2138.

Gajic M, Zaripheh S, Sun F, Erdman JW Jr (2006) Apo-8'-lycopenal and apo-12'-lycopenal are metabolic products of lycopene in rat liver. J Nutr 136: 1552-1557. 
Gann PH, Hennekens CH, Ma J, Longcope C, Stampfer MJ (1996) Prospective study of sex hormone levels and risk of prostate cancer. J Natl Cancer Inst 88: 1118-1126.

Giovannucci E, Ascherio A, Rimm EB, Stampfer MJ, Colditz GA, Willett WC (1995) Intake of carotenoids and retinol in relation to risk of prostate cancer. J Natl Cancer Inst 87: 1767-1776.

Hessel S, Eichinger A, Isken A, Amengual J, Hunzelmann S, Hoeller U, Elste V, Hunziker W, Goralczyk R, Oberhauser V, von Lintig J, Wyss A (2007) CMO1 deficiency abolishes vitamin A production from beta-carotene and alters lipid metabolism in mice. J Biol Chem 282: 33553-33561.

$\mathrm{Hu}$ KQ, Liu C, Ernst H, Krinsky NI, Russell RM, Wang XD (2006) The biochemical characterization of ferret carotene- $9^{\prime}, 10^{\prime}$ monooxygenase catalyzing cleavage of carotenoids in vitro and in vivo. J Biol Chem 281: 19327-19338.

Huggins C, Hodges CV (2002) Studies on prostatic cancer: I. the effect of castration, of estrogen and of androgen injection on serum phosphatases in metastatic carcinoma of the prostate. 1941. J Urol 168: 9-12.

Khachik F, Pfander H, Traber B (1998a) Proposed mechanisms for the formation of synthetic and naturally occurring metabolites of lycopene in tomato products and human serum. I Agric Food Chem 46: 4885-4890.

Khachik F, Steck A, Niggli U, Pfander H (1998b) Partial synthesis and structural elucidation of the oxidative metabolites of lycopene identified in tomato paste, tomato juice, and human serum. I Agric Food Chem 46: 4874-4884.

Kim SJ, Nara E, Kobayashi H, Terao J, Nagao A (2001) Formation of cleavage products by autoxidation of lycopene. Lipids 36: 191-9.

King TJ, Khachik F, Bortkiewicz H, Fukushima LH, Morioka S, Bertram JS (1997) Metabolites of dietary carotenoids as potential cancer preventive agents. Pure and Appl Chem 69: 2135-2140.

Kopec RE, Riedl KM, Harrison EH, Curley RW,Jr, Hruszkewycz DP, Clinton SK, Schwartz SJ (2010) Identification and quantification of apo-lycopenals in fruits, vegetables, and human plasma. I Agric Food Chem 58: 3290-3296.

Lian F, Smith DE, Ernst H, Russell RM, Wang XD (2007) Apo-10'-lycopenoic acid inhibits lung cancer cell growth in vitro, and suppresses lung tumorigenesis in the $\mathrm{A} / \mathrm{J}$ mouse model in vivo. Carcinogenesis

Lindqvist A, He YG, Andersson S (2005) Cell type-specific expression of beta-carotene $9^{\prime}, 10^{\prime}$-monooxygenase in human tissues. I Histochem Cytochem 53: 1403-1412.

Lindshield BL, Canene-Adams K, Erdman JW Jr (2007) Lycopenoids: Are lycopene metabolites bioactive? Arch Biochem Biophys 458: 136140.

Linnewiel K, Ernst H, Caris-Veyrat C, Ben-Dor A, Kampf A, Salman H, Danilenko M, Levy J, Sharoni Y (2009) Structure activity relationship of carotenoid derivatives in activation of the electrophile/ antioxidant response element transcription system. Free Radic Biol Med 47: 659-667.

Mein JR, Lian F, Wang XD (2008) Biological activity of lycopene metabolites: Implications for cancer prevention. Nutr Rev 66: 667-683.

Roberts JT, Essenhigh DM (1986) Adenocarcinoma of prostate in 40-year-old body-builder. Lancet 2: 742 .

Shaneyfelt T, Husein R, Bubley G, Mantzoros CS (2000) Hormonal predictors of prostate cancer: A meta-analysis. J Clin Oncol 18: 847853.

Wyss A (2004) Carotene oxygenases: A new family of double bond cleavage enzymes. I Nutr 134: 246S-250S.

Zaripheh S, Nara TY, Nakamura MT, Erdman JW Jr (2006) Dietary lycopene downregulates carotenoid 15,15'-monooxygenase and PPAR-gamma in selected rat tissues. J Nutr 136: 932-938.

Zhang H, Kotake-Nara E, Ono H, Nagao A (2003) A novel cleavage product formed by autoxidation of lycopene induces apoptosis in HL-60 cells. Free Radic Biol Med 35: 1653-1663. 